\title{
Child Neglect: What Is It, What Causes It and How We Can Minimize It?
}

\author{
Ami Rokach*1, Karen M. Ohayon-Inger ${ }^{2}$ \\ ${ }^{1}$ York University, Toronto Canada. \\ ${ }^{2}$ College of Law and Business, Tel Aviv, Israel.
}

*Corresponding Author: Ami Rokach, York University, Toronto, Canada.

Received Date: September 10, 2020 | Accepted Date: December 27, 2021 | Published Date: January 01,2022

Citation: Ami R and K M. O-Inger. (2022) Child Neglect: What Is It, What Causes It and How We Can Minimize It?. International Journal of Clinical Case Reports and Reviews. 10(1); DOI: 10.31579/2690-4861/175

Copyright: (c) 2022 Ami Rokach, This is an open-access article distributed under the terms of the Creative Commons Attribution License, which permits unrestricted use, distribution, and reproduction in any medium, provided the original author and source are credited.

\section{Abstract}

Almost all forms of abuse include child neglect, and still the professional and clinical community is only now starting to focus attention to this phenomenon and its short- and long-term effects. This paper begins with defining child neglect, what causes parents to neglect the children which they are supposed to love and protect, and the protective factors that parents and the community must be aware of and utilize in protecting kids.

Key words: child abuse; child neglect; parents; prevalence of child neglect; intergenerational transmission of abuse

\section{Introduction:}

Frequently, child neglect is classified as child abuse, however neglect has its own components and there is an absence of research on the subject. Over the years, Garbarino and Collins (1999) pursued to define why there has not been much research on neglect. First, neglect is less striking than a child's fractured bone or a depiction of a father sexually assaulting his kid. Second, it is not as recognizable, and more onerous to identify. And finally, treatment focuses on teaching the neglectful parent how to properly care for the child rather than abstaining from assault. (Dubowitz, 2007; Erikson and Egeland, 2011; Stevenson, 2007; Taylor and Daniel, 2005).

\section{What is child neglect?}

Although viewing the neglected kids might promptly demonstrate their genuine anguish, neglect cannot be understood in social or legal terms (Erickson \& Egeland, 2011). Neglect is challenging to describe since it is an act of carelessness, rather than deterioration (Horwath, 2007; Joffe, 2002; McSherry, 2011). Numerous actions can be classified as "neglect", and they might differ substantially, notably in affiliation to the child's developmental level (DePanfilis, 2006; Erikson and Egeland, 2011; McSherry, 2011). According to Joffe (2002), there are three forms of neglect: Physical neglect, which includes poor supervision, abandonment, and inability to satisfy the kid's fundamental requirements; medical neglect, which includes the denial or delay in obtaining the child the health treatment that they require; allowing truancy, failing to send the kid to school, or failing to address the child's specific educational requirements are all examples of educational neglect. (see also DePanfilis, 2006; Pearl, 2002). To that which was added, Erickson and Egeland (2011) suggest that emotional neglect exists as well, manifested as a lack of attention to a child's emotional needs, behavior disorder(s), or mental health concerns. Cantwell (1997) expanded on these factors, arguing that emotional neglect also includes a parent's failure to properly connect with their kid and ignoring their child's development of self-esteem. A kid who has been emotionally ignored is subjected to stimulation neglect, and their parents put their emotional and neurological development at risk.

An emotionally neglected kid, for example, will have their bottle elevated such that no contact occurs, rather than experiencing touch and its role in developing healthy connection. Furthermore, such a child will be deprived of the opportunity to develop hand-eye coordination and other perceptual abilities that come with being fed by hand. Neglected adolescents are hindered from internalizing language that will be crucial in future social connections and problem-solving situations if their parents speak with them using directives rather than beneficial language stimulants. These kids are ill-equipped to perform well in school. (Cantwell, 1997; McSherry, 2011). Children who are neglected are denied the ability to enhance both gross and fine motor abilities. They may be forbidden by their parents from leaping and generally enjoying the world in the way that healthy children do. Fine motor abilities are developed in infants by stroking their parents' faces with their small fingers, and they are subsequently encouraged to perform various activities such as puzzle creation and painting to further improve these skills. Neglected children whose parents are uninterested in partaking in such "immature" activities, on the other hand, are deprived of these opportunities and may have 
delays in the development of their fine motor abilities (Cantwell, 1997). Contemporary norms and cultural values have a strong impact on the concept of neglect. (Crosson-Tower, 2014). In today's culture, parents are expected to provide enough food, shelter, clothes, medical care, education, protection, and moral and social direction to their children. (DePanfilis, 2006; Garbarino \& Collins, 1999; Gaudin, 1999; Joffe, 2002; McSherry, 2011).

Polansky and colleagues contributed a more succinct operational description of the occurrence: "Child neglect may be defined as a condition in which a caretaker responsible for the child either deliberately or by extraordinary inattentiveness permits the child to experience available present suffering and/or fails to provide one or more of the ingredients generally deemed essential for developing a person's physical, intellectual, and emotional capacities" (1980, p. 5). They considered behaviors such as food preparation, medical treatment, leaving the kid alone, home adequacy and safety, giving the child suitable sleeping and living circumstances, and cleanliness of the place of residence in their attempts to build an assessment instrument for child neglect. (Hally et al., 1980).

\section{Stats on neglect}

Although globally there is a shortage of research regarding child neglect (Stoltenborgh et al., 2013), the worldwide prevalence of child neglect is approximately $16 \%$ for physical neglect and $18 \%$ neglect for emotional neglect which places child neglect as a major world health and social problem (Kubolsky et al., 2020). In the United States child neglect is four times more common than physical abuse and almost nine times more common than sexual abuse (United States Department of Health and Human Services [USDHHS], 2019). In fact, 75\% of maltreatment reports to Child Protective Services are in regard to the neglect of children. According to Kobulsky et al. (2020) studies which reviewed a large number of prevalence cases, two were lower middle income, one was from a low-income country, six were upper middle income, and six of them were from high income countries. Examining them according to their geographical location, nine studies covered Asia, five were of European countries, four from the Americas, and two of African countries. Rates of overall lifetime neglect range from $9 \%$ in Sweden to $55 \%$ in Taiwan, both represent the high-income countries. In upper middle-income countries, the rates varied from twenty three percent in Romania to eighty four percent in Yazd Province, Iran. In lower middleincome countries, general lifetime neglect rates varied from twenty nine percent in Vietnam to fifty nine percent in Kenya. In the single lowincome country study of Burundi, the currency of physical neglect was eighty nine percent and emotional neglect was ninety four percent.

\section{Neglect cross culturally}

The topic of neglect whether physical or emotional, has not been extensively studied across cultures compared to the study of physical abuse. Putnick et al. (2012) discovered that on the higher range of neglect related cases were parents in China, Jordan and Kenya while parents in Italy, Sweden, The United States and Colombia scored on the lower range overall. This shows us that culture plays a substantial role in how parenting is seen and assessed. In some cultures, an example of this could be caregiving by siblings. This could play a beneficial role in child development (both by the receiver and the provider) or it may be considered inappropriate or damaging (East, 2010).

Socio-economic constraints in certain regions of the world are known to contribute to neglectful behavior towards children by their caregivers (Mesman et al., 2020). In any culture it is harmful to neglect a child, but the parent's conception about what exactly is harmful for their children are typically rooted in their actions' need for an intervention. For example, in the West, the lack of clean clothes or adequate emotional health for your child could be seen as neglectful although this is a very common occurrence in severely impoverished countries. This could result in behavior that can seem neglectful but may simply be the lack of capabilities to adequately care for their child (social, emotional andlor cognitive). Unfortunately, this may not change the effect of child development regardless of the caregiver's intentions. The need for intervention may be excused based on the parents' standards of what constitutes as maltreatment. Barnett and colleagues (1993) discovered that in poor countries where there is a lack of resources, there could be a higher threshold for intervention and a more laxed definition of maltreatment. This could mean that before any steps are taken to intervene, maltreatment may reach a very high level. The western research literature is not the only studies where inconsistences in the definition of child maltreatment are found. In cross cultural differences (Raman \& Hodes, 2012) you can find non-Western or low medium Human Development Index countries (Suriname, the Syrian Arab Republic, Yemen, Sierra Leone and Ghana) where authoritative parenting styles are more widely accepted than in western or high Human Development Index countries and an example of this would be the use of corporal punishment (Lansford \& Deater-Deckard, 2012; Van der Kooij et al., 2017).

There is a term for parents who put extreme pressure on the performance of their children, who punish frequently and take on a more hostile approach. The term for this is "Tiger parents". Surprisingly these individuals also inhabit the trait of warmth (Chua, 2011). Some parenting strategies of these "Tiger Parents" are the use of harsh emotional control, threats, or insults which in the West world would be considered emotional abuse. Regardless of the culture, socio economic status, the parental intent and circumstances of the caregiver, the children's development is still harmed. Their parenting strategies involve what we in the West world would perceive as emotional abuse, such as the use of harsh emotional control, insults, or threats. Children are harmed by them, regardless of the culture or parental intent.

\section{Causes of child neglect}

Polansky and colleagues (1983) grouped the child neglect reasons into three categories. The first was of an economic nature, highlighting the importance of poverty and material deprivation on how parents treat their children. The ecological refers to how a family acts in relation to the wider social milieu in which it functions. Finally, individual variations among parental personalities are referred to as personalistic.

Economic factors - Neglect is viewed as a reaction to stress, and poverty is a constant source of stress. Many parents who are negligent, live in poverty or live in a way that is poor. (Cantwell, 1997; Dubowitz, 1999; Joffe, 2002; Smith \& Fong, 2004; Stevenson, 2007). Nevertheless, not all poor families are negligent, hence poverty cannot be considered a major factor to child neglect. (Cantwell, 1997; Erickson \& Egeland, 2011; Joffe, 2002; Smith \& Fong, 2004; Taylor \& Daniel, 2005).

Poorness, according to Crosson-Tower (2014), does not imply neglect. Crittenden (1999) made several intriguing discoveries while attempting to comprehend this seemingly misleading link between poverty and neglect. She says that low socioeconomic status encompasses a variety of characteristics linked to poverty, including unemployment, insufficient education, social isolation, a large family, and childbearing among unmarried teens. Attempts to better the family's financial situation, or even to stop their poverty, did not alleviate their neglect of their children.

Ecological reasons - The ecological perspective sees the individual as a component of the environment, interacting with it. Wolock and Horowitz (1979) conducted an early research in which they examined communities with maltreated parents and discovered that they were more worn down and hostile than normal, resulting in low morale among the residents. Recent research has backed up such claims (DePanfilis, 2006; Drake \& Pandy, 1996; Korbin et al., 2000). If a parent's capacity to care for their children is impacted by the culture in which they live, then feeling 
abandoned by their environment may lead to negligent parenting. When considering negligent parents from an ecological standpoint, we must consider them in the context of their neighborhood, culture, and society. In analyzing the family's functioning, it is critical to understand the child rearing ideals entrenched in diverse ethnic and cultural backgrounds. The family's strengths, as well as the family's community and their ability to give resources and social support to their loved ones, must all be understood. When it comes to intervention, the ecological approach stresses social support for the family. According to Crosson-Tower (2014), neglectful families are not only difficult for society to tolerate, but they also cause issues for the system when help is provided.

Individualistic reasons - According to Crittenden (1999) and Cantwell (1997), neglect begins with the development of the individual parent and their information processing techniques. Our conduct will be determined by how we process information. The information we acquire can have an impact on our intellect or mood. Cognition, in most cases, tells us which activities will result in which sort of affect, and hence drives our behavior. Affect usually has anything to do with knowledge regarding our safety or danger. Affect is defined as "experiences in feeling states that inspire protective or loving behavior, and that encourage exploration and learning when feelings of discomfort are low." (Crittenden, 1999, p. 51).

\section{Helping neglectful families}

Aiming to assist negligent families is a difficult task. To begin with, there are several examples of families like this, and most social workers are already overburdened. Next, many novice workers prefer to overlook these families, and it is difficult to substantiate maltreatment even when it is proven. Because neglect is usually associated with material need, neglect in rich homes may go unnoticed. In these households, neglect is typically passed down from generation to generation. Furthermore, according to Crittenden (1999), negligent parents interpret information incorrectly and in a way that makes interacting with them nearly impossible. To make matters worse, when experts recognize that they are dealing with a negligent family, they sometimes only have a limited number of concrete resources to provide (Crosson-Tower, 2014).

\section{The neglected child}

Neglect is a common occurrence that affects the entire family. Usually, all of the children are ignored, rather than just one. Even when these children reach maturity, when they are less reliant on their parents and affection, the emotional toll of their neglect continues to impact them. According to available data, $78.3 \%$ of maltreatment victims in the United States were neglected (U.S. Department of Health and Human Services et al., 2011). The image of a neglected toddler will stay with you for a long time. Dr. Fontana, a physician at the New York Foundling Hospital, accurately described this sensation. He detailed what he observed when he arrived at his hospital, which held 320 traumatized youngsters. "What my colleagues and I observed were blank-eyed kids who couldn't respond to a pleasant touch and turned their faces to the wall. Infections that had gone untreated in children. Children whose hair had been lice-free for a while. Children with bruised features, maybe with a small dislocation or two, and large eyes in hollow faces. Dehydrated children who were on the verge of passing out. The most amazing guttural language was employed by small toddlers who were hardly able to speak. Children who had been fed meals that were completely inappropriate. Kids who have residues of medicine that should not have been given to children. Children who appeared to be physically healthy yet appeared to be profoundly lost and who never smiled or cried" (1976, p. 20).

\section{Effects of child neglect}

While certain physical signs, such as those seen in physically abused children, are not readily apparent, others are. We'll look at them based on the child's age.
Infancy and early childhood - Child neglect is defined by the nonorganic failure to thrive (NFTT) syndrome, which is characterized by an infant's weight and height falling below the fifth percentile while previously being within normal ranges, as well as a delay in psychomotor development (Dubowitz \& Black, 2002; Joffe, 2002; Wright, 2005). A kid who continues to show little interest in eating, is behind in age-appropriate development, and responds only little to the surroundings, is at risk of failing to thrive (Wright, 2005). Though NFTT might be caused by parents who are unsure how to feed their children or who lack the financial means to do so, it can also be a sign of more serious issues.

Infants are very aware of their caregivers' emotions and attitudes. They may have unfavorable reactions to parents who appear ambivalent, aggressive, emotionally unavailable, or whom the child perceives to be excessively demanding. In addition, NFTT babies frequently show minimal affect. Feeding them becomes a challenge since they have lost their capacity to suck and may be uninterested in food. As a result, their parents describe them as unlovable or refusing to be held. The NFTT syndrome has been blamed primarily on maternal deprivation. The infant's condition reflects the entire family's maladaptation and estrangement (DePanfilis, 2006; Dubowitz \& Black, 2002; Joffe, 2002; Wright, 2005). Children between the ages of 18 months and 16 years may develop psychosocial dwarfism (PSD), also known as hyposomatotropism, deprivational dwarfism, and abuse dwarfism, as a result of parental neglect. Abnormally poor growth is promoted by emotional deprivation. These youngsters have strange feeding patterns, indiscriminate eating, food theft, nocturnal roaming, or severe exhaustion as behavioral issues. Enuresis (uncontrollable urination) or encopresis (fecal soiling) might make the situation worse. Weight growth is naturally influenced by a lack of emotional stimulation and inadequate diet, although the effects are not always obvious. Neglected infants may have a lack of muscular tone and may even be unable to hold their own weight. These newborns lack confidence in their surroundings and will not make eye contact, grin, or squeal as normally as other babies (Crosson-Tower, 2014).

\section{Young children}

Neglected children of all ages have poor motor skills and linguistic development delays. Long-term inattention to a child's food or emotional requirements results un a child with dull skin and hair. The child's bloated stomach and thin limbs are obvious signs of severe malnutrition. Limited emotional stimulation throughout childhood causes flat affect and extreme apathy. Neglectful parents frequently ignore medical concerns and fail to take their children to regular medical checks, averting a circumstance in which a physician may have discovered a problem with the kid. Likewise, vaccinations may not be provided to the kid, and preventable childhood illnesses can become a terrible part of the life of the neglected child. Hair lice, which is often left untreated by the overworked and emotionally detached parent, is another medical sign observed in neglected children (DePanfilis, 2006; Smith \& Fong, 2004; Stevenson, 2007; Taylor \& Daniel, 2005).

Neglected children also have problems with social skills and language development, making it difficult for them to comprehend even the most fundamental activities. Naturally, this will lead to a breakdown in communication with other youngsters. These youngsters get lonelier and more estranged from others as they grow older. Neglected children are punished when their activities upset the caregiver since there are no regular norms in place. It's hardly unexpected that neglected youngsters don't establish an internalized set of guidelines to guide them, preferring instead to follow external instructions. For example, they will not stop from stealing because they believe it is wrong, but rather because they believe they will be caught. They also have a hard time deferring satisfaction since they never know if their pleasures will be there tomorrow. As a result, they learn to "take it when it's there." 


\section{Adolescents}

Neglected kids may opt to leave their family throughout adolescence. Moving out, fleeing, or becoming pregnant sets in motion their abandonment once more. Neglected children are isolated from those who have learned to compete in society, and as a result, they associate with others from similar backgrounds, repeating the cycle with their own children (Crosson-Tower, 2014).

\section{The neglecting parents}

To be honest, it's tough to comprehend why a parent would allow his or her family to descend into the chaos, uncertainty, apathy, and filth that some negligent families' homes show. However, a small percentage of the population does so. Due to their lack of experience with individuals from other backgrounds and weak social skills, these people frequently do not stray from their existing lives. The manner they were reared and burdened by their own anger and grief leads to a lack of attention for their own children's needs; this is especially true of single parent women who are unable to maintain and commit to a long-term romantic relationship. According to research on how these parents react to their children, it appears that they are unconcerned about their children and discipline them to obtain some peace and quiet rather than to teach them survival skills. They have a limited ability to solve problems or create long-term objectives for themselves and their children. They've been defined as floating mindlessly and idly in a harsh environment. We observe a loop of bad development for their children, especially in terms of education and interpersonal relationships since they are poorly equipped to instill optimism in their children. As a result, these individuals are more likely to have negative school experiences and have unsatisfactory adult relationships as they grow older.

Neglectful parents are less connected with others, have poor impulse control, struggle to organize and plan, and, as a result, are unsatisfied with their accomplishments. When compared to the general population, they were shown to have lower IQ scores and a lack of respect for societal norms and values (Smith \& Fong, 2004; Stevenson, 2007; Taylor \& Daniel, 2005). Cantwell concisely recognized that these parents' actions toward their children are the result of a lack of information, judgment, and drive, as she describes in her book (1999). These parents were found to be lacking in knowledge in areas such as understanding that a baby must be fed every three to four hours, having appropriate housekeeping and cooking abilities, and understanding that their kid requires stimulation, nurturance, medical care, and punishment boundaries. Because they have a warped sense of what role they play in their lives, neglectful parents may not notice when their child is unwell or when they need time alone.

These parents may lack the motivation or energy to learn how to parent correctly. They just don't have a benchmark to compare themselves against. They are generally seen as childish in that they lament the lack of affection and attention from their own parents and think that their parenting 'careers' began at an early age (Hampton, 2003; Polansky et al., 1972; Stevenson, 2007; Taylor \& Daniel, 2005).

\section{Trying to explain why parents neglect their children}

Polansky and a group of colleagues (1972) looked at the issue of neglecting moms. They discovered that these ladies had personality disorders. They identified five categories of neglectful mothers: (1) apathetic-ineffective; (2) impulse-driven; (3) mentally retarded; (4) reactive depressive; and (5) borderline or psychotic. The apathetic-futile and impulse-ridden groups encompass the majority of negligent moms. When looking at the role of dads in child neglect, it was discovered that the mother is the primary source of neglect. Women who are described as apathetic-useless appear to have given up on life (Polansky et al., 1983). They have a flat expression, as if they had given up on life since there is nothing worth doing. This mother is emotionally numb, lonely, and secluded. Her personal connections are tumultuous and provide her little joy. She is obstinately pessimistic, uncommitted, and thinks in categorical terms. Because she lacks the ability to conceive, she thinks in terms of black and white. When others don't understand her, she may become irritated. She is unable to get insight and is nearly unable to observe herself.

The problem for social workers is that a mother's sense of futility is very contagious. Her lack of understanding causes the novice worker to have questions about the diagnosis. Even the most seasoned workers are susceptible to the "nothing is worth doing" approach. The worker will not be understood (and may even be blocked out) if they do not use the most basic language. Intervention is exceedingly tough. The impulsive mother is one that has a low frustration tolerance, an inability to wait pleasure, and acts with exceedingly bad judgment (Polansky et al., 1983). She may put out greater effort in her endeavors, but this effort is generally oriented toward fulfilling her personal wants rather than those of her children. Her house may not be as filthy and chaotic as the indifferent mother's is, but she lacks consistency. She has a history of poor judgment and unpredictable behavior when it comes to her children. She has failed to appropriately safeguard and nurture her children. And her children will have learnt through the years that the only certainty is that tomorrow will be different.

Intellectual disability, or cognitive impairment - does not rule out the potential of good parenting, but it does make it easier to overlook it. Only a tiny fraction of negligent moms, on the other hand, are intellectually retarded. Those who are, however, require proper care.

Reactive-Depressive moms are unable to adapt to many parts of their lives and are depressed as a result of this incapacity. As a result, they are unable to parent effectively. Other circumstances that might cause depression also include birth of a second child, a spouse's abandonment, or the loss of a loved one.

The psychotic mother - Only a tiny fraction of neglectful households have a psychotic mother. In many cases, the parents' incapacity to look beyond their deluded reality is to blame for their children's neglect. When the parent isn't hallucinating, he or she can cater to the children's needs, but it's hard for them to parent well otherwise. Some parents have a borderline reality orientation, which means they can go in and out of psychosis, causing significant uncertainty in the lives of their children. They are frequently regarded as significantly different by healthcare personnel because to their shifting perception of reality (Crosson-Tower, 2014).

Neglectful parents' information processing - Parental information processing abilities have previously been linked to child neglect. Crittenden (1999) proposed that negligent parents, particularly females, had problems processing information (see Personalistic Individual Causes above). Neglectful parents, according to Crittenden, come into three categories: disorganized neglect, emotional neglect, and sad neglect. Parents that display disorganized neglect are inconsistent with their children, go from one crisis to the next, and are frequently perceived as having families with numerous issues. In these families, emotion takes precedence over cognition. As a result, family members react emotionally rather than rationally.

Substance abuse - Any form of child maltreatment can be caused by parental substance misuse. Parents who are under the influence of drugs or alcohol can and do abuse their children physically, sexually, or emotionally. Even if they do not intentionally mistreat their children, it is evident that they cannot be totally present for them when under the influence, resulting in neglect. Prenatal abuse has only lately been recognized as a form of child maltreatment. It entails women taking chemicals that are known to be hazardous to their unborn fetuses, which can result in a variety of medical issues for the unborn kid. 
Premature birth, infectious illnesses, fetal alcohol syndrome (FAS), intrauterine growth retardation (IUGR), and central nervous system problems are all risks for children born to substance-abusing mothers. Irritability, tremors, high-pitched screaming, seizures, diarrhea, frequent vomiting, and sleep disturbances are all possible symptoms in these newborns (Chasnoff \& Lowder, 1999; Kelly, 2002; Spohr \& Steinhausen, 2011; Straussner \& Fewell, 2006). Later in life, these youngsters have difficulty learning, solving problems, and understanding cause and consequence. They are frequently uncoordinated and rash (Kelly, 2002; Spohr \& Steinhausen, 2011; Straussner \& Fewell, 2006). Mothers who use injectable drugs, prostitutes, or have had numerous sexual partners may pass HIV to their unborn children through their breast milk after they are born. The prognosis for these children is bleak. The future of these youngsters is still unknown (Kelly, 2002; Sharpe, 2005).

Children and Substance Abuse - Not all moms use drugs or alcohol while pregnant. Some of these activities begin when the youngster is older. Even though other substances may be just as harmful to a parent's capacity to parent, crack remains one of the most popular street drugs owing to its accessibility and cost. Other accessible drugs include heroin, hallucinogens, cocaine, and morphine, all of which result in parents delivering poor care to their children. Under the effect of the medication, you will experience slowed responses, exhilaration, and drowsiness. Their addiction to these narcotics may cause them to be closed off to any aid from social services.

Domestic abuse and neglect - When a family is subjected to domestic violence, they have little time to care for their children. Bancroft and colleagues (2012) characterized the male batterer as someone who sees his children as a nuisance. He frequently knows very little about them, including their academic achievements, strengths, and goals. He's completely oblivious to the impact his aggressive behavior has on his children. At other instances, the batterer tries to persuade his children to join him in his fight against their mother. The abused party's mother may be so preoccupied with protecting herself that she is unable to satisfy her children's needs (See Crosson-Tower, 2014).

\section{Intergenerational child abuse and neglect}

Preventing child abuse and neglect is considered a challenging task. One of the reasons for it being so difficult, is that neglectful parenting is transferred from one generation to the next (Bartlett et al., 2017). It is indicated by findings that there is a higher risk of committing child mistreatment by parents who have a history of suffering from abuse and neglect as children themselves compared to those who were not mistreated (Heyman \& Slep, 2002; Newcomb \& Locke, 2001; Pears \& Capaldi, 2001; Thornberry et al., 2012). Typically, the focus of this research surrounds only one single type of maltreatment

(e.g., physical abuse alone) or it can be a combined version of two or more types (e.g., physical abuse and/or neglect and/or sexual abuse) (Berzenski et al., 2014). Researchers tend to ignore various forms of child abuse, neglect and maltreatment caused by discrepancies in behavior patterns. Therefore Berzenski et al. (2014) suggest “...[that] a focus on subtype specificity will reveal that, just as the experiences of subtypes of maltreatment have different correlates and consequences, the continuity of these experiences across generations may vary as well" (p. 117). Homotypic continuity of maltreatment (i.e., type-to-type correspondence from one generation to the next) is more widespread compared to heterotypic continuity (i.e., different types in each generation). It was discovered by Kim (2009) that parents tended to be more neglectful to their own children if they were neglected as children themselves rather than resort to an alternate form of abuse. (i.e., physical abuse). (Bartlette et al 2017) conducted a study that resulted in several understandings that could be interpreted in different ways: 1 . a mother who was neglected or abused at childhood has a higher chance of doing so with her own children which paints the mother as both a victim and a perpetrator. 2 . chances increase by fifty percent to children whose mothers have a history of maltreatment that they themselves will suffer the same treatment compared to those with mothers who are treated well growing up. (See also Valentino et al., 2012). 3. neglect was sixty percent more common in mothers who were neglected growing up along with intergenerational rates being highest for type-to-type transmission. The authors determined by studies that "...taking a systemic approach in considering both maternal and child histories provide a more nuanced understanding of children's maltreatment. We view our results regarding intergenerational transmission as quite robust, and sobering, given that they held across variations in home visiting program status and child age (since maternal age at childbirth and race/ethnicity did not contribute to the model they were not included)" (p. 92).

To conclude, child neglect is clearly a form of child abuse. It has severe consequences and has both short and long-term effects on the children who are subjected to it. It is incumbent on us, as mental health professionals and as a society, to be aware of the problem, learn to recognize the signs which the neglected children display, and act with the children and their parents in ameliorating the situation. It is unquestionable, that child neglect cannot and should not be ignored.

\section{References}

1. Bancroft, L., Silverman, J. G., \& Ritchie, D. (2012). The batterer as parent: Addressing the impact of domestic violence on family dynamics (2nd ed.). Sage Publications.

2. Barnett, D., Manly, J. T., \& Cicchetti, D. (1993). Defining child maltreatment: The interface between policy and research. In D. Cicchetti, \& S. L. Toth (Eds.), Child abuse, child development and social policy. 7-73.

3. Bartlett J D, Kotake C, Rebecca Fauth R \& Easterbrooks M.A. (2017). Intergenerational transmission of child abuse and neglect: do maltreatment type, perpetrator, and substantiation status matter? Child Abuse \& Neglect. 63; 84-94.

4. Berzenski S. R, Yates T M, \& Bryon E. (2014). A multidimensional view of continuity in intergenerational transmission of child maltreatment. In J. E. Korbin, \& R. D. Krugman. Handbook of Child Maltreatment. 115-129.

5. Cantwell H. B. (1997). The neglect of child neglect. In M. E. Hefler, R. S. Kempe \& R. D. Krugman, The battered child. $347-$ 373.

6. Chasnoff I J, \& Lowder L A. (1999). Prenatal alcohol and drug use and risk for child maltreatment: A timely approach to intervention. In H. Dubowitz (Ed.), Neglected children: Research, practice, and policy. 132-155.

7. Chua, A. (2011). Battle hymn of the tiger mother. Bloomsbury Publishing.

8. Clément M È, Bérubé A, \& Chamberland C. (2016). Prevalence and risk factors of child neglect in the general population. Public health. 138; 86-92.

9. Clément M, Bérubé A, Goulet M, \& Hélie S. (2020). Family Profiles in Child Neglect Cases Substantiated by Child Protection Services. Child Indicators Research. 13(2); 433-454.

10. Crittenden P M. (1999). Child neglect: Causes and contributors. In H. Dubowitz Neglected children: Research, practice, and policy. 47-68.

11. Crosson-Tower C. (2014). Understanding child abuse and neglect. 9th Ed.

12. DePanfilis D. (2006). Child neglect: A guide for prevention, assessment, and intervention. U.S. Dept. of Health and Human Services, Administration for Children and Families, 
Administration on Children, Youth and Families, Children's Bureau, Office on Child Abuse and Neglect.

13. Dickson D J, Laursen B, Stattin H, \& Kerr M. (2015). Parental supervision and alcohol abuse among adolescent girls. Pediatrics. 136(4); 617-624.

14. Drake B \& Pandey S. (1996). Understanding the relationship between neighborhood poverty and specific types of child maltreatment. Child Abuse \& Neglect. 20(11):1003-1018.

15. Dubowitz, H., \& Black, M. (2002). Neglect of children's health. In J. E. B. Myers \& American Professional Society on the Abuse of Children (APSAC) (Eds.), The APSAC handbook on child maltreatment. 103 -124.

16. Dubowitz H. (2007). Understanding and addressing the neglect of neglect: Digging into the molehill. Child Abuse \& Neglect. 31(6):603-606.

17. Dufour S, Lavergne C, Larrivée M C, \& Trocmé N. (2008). Who are these parents involved in child neglect? A differential analysis by parent gender and family structure. Children and Youth Services Review. 30(2):141-156.

18. East P L. (2010). Children's provision of family caregiver: Benefit or burden? Child Development Perspectives. 4(1):5561.

19. Erickson M F, \& Egeland B. (2011). Child neglect. In J. E. B. Myers \& American Professional Society on the Abuse of Children APSAC, The APSAC handbook on child maltreatment. 103-124.

20. Fontana V J. (1976). Somewhere a child is crying: Maltreatment - causes and prevention. New American Library.

21. Garbarino J \& Collins C C. (1999). Child neglect: The family with a hole in the middle. In H. Dubowitz, Neglected children: Research, practice, and policy. 1-23.

22. Gaudin J M. (1999). Child neglect: Short - term and long - term outcomes. In H. Dubowitz (Ed.), Neglected children: Research, practice, and policy. 89-108.

23. Geoffroy M C, Pinto Pereira S, Li L \& Power C. (2016). Child neglect and maltreatment and childhood-to-adulthood cognition and mental health in a prospective birth cohort. Journal of the American Academy of Child and Adolescent Psychiatry. 55(1):33-40.

24. Guterman N B, Lee S J, Taylor C A, \& Rathouz P J. (2009). Parental perceptions of neighborhood processes, stress, personal control, and risk for physical child abuse and neglect. Child abuse \& neglect. 33(12): 897-906.

25. Gutman L M, Joshi H, Parsonage M, \& Schoon I. (2018). Gender-specific trajectories of conduct problems from ages 3 to 11. Journal of Abnormal Child Psychology. 46(7):1467-1480.

26. Hally C, Polansky N F, Polansky N A \& National Center on Child Abuse and Neglect (U.S.). (1980). Child neglect, mobilizing services. U.S. Dept. of Health and Human Services, Office of Human Development Services, Administration for Children, Youth, and Families, Children's Bureau, National Center on Child Abuse and Neglect.

27. Hampton R L. (2003). Black family violence: Current research and theory. Lexington Books.

28. Heyman R E, \& Slep A M S. (2002). Do child abuse and interparental violence lead to adulthood family violence? Journal of Marriage and Family. 64(4): 864-870.

29. Hildyard K L, \& Wolfe D A. (2002). Child neglect: Developmental issues and outcomes. Child Abuse \& Neglect. 26(6-7):679-695.

30. Horwath J. (2007). Child neglect: Identification and assessment. Palgrave Macmillan.
31. Joffe M. (2002). Child neglect and abandonment. In A. P. Giardino \& E. R. Giardino, Recognition of child abuse for the mandated reporter. 39-54.

32. Kelly S J. (2002). Child maltreatment in the context of substance abuse. In J. E. B. Myers \& American Professional Society on the Abuse of Children (APSAC) (Eds.), The APSAC handbook on child maltreatment. 103-124.

33. Kim J. (2009). Type-specific intergenerational transmission of neglectful and physically abusive parenting behaviors among young parents. Children and Youth Services Review. 31(7):761-767.

34. Kim K, Mennen F E \& Trickett P K. (2017). Patterns and correlates of co-occurrence among multiple types of child maltreatment. Child \& family social work. 22(1):492-502.

35. Kobulsky J M, Dubowitz H \& Xu Y. (2020). The global challenge of the neglect of children. Child Abuse \& Neglect.

36. Korbin J E, Coulton C J, Lindstrom Ufuti H \& Spilsbury J. (2000). Neighborhood views on the definition and etiology of child maltreatment. Child Abuse \& Neglect. 24(12):1509-1527.

37. Lansford J. E \& Deater Deckard K. (2012). Childrearing discipline and violence in developing countries. Child Development. 83(1):62-75.

38. Maguire S. A, Williams B, Naughton A. M, Cowley L E, Tempest V, Mann M. K, Teague M, \& Kemp A M. (2015). A systematic review of the emotional, behavioural and cognitive features exhibited by school-aged children experiencing neglect or emotional abuse. Child: care, health and development. 41(5):641-653.

39. Mc Sherry D. (2011). Lest we forget: Remembering the consequences of child neglect - A clarion call to "feisty advocates". Child Care in Practice. 17(2):103-113.

40. Mennen F E, Kim K, Sang J \& Trickett P K. (2010). Child neglect: definition and identification of youth's experiences in official reports of maltreatment. Child abuse \& neglect. 34(9):647-658.

41. Mesman J, Branger M, Woudstra M.L, Emmen R, Asanjarani F, Carcamo R, Hsiao, C, Mels C, Selcuk B, Soares I, Ginkel J. V, Wang L, Yavuz M \& Alink L. (2020). Crossing boundaries: A pilot study of maternal attitudes about child maltreatment in nine countries. Child Abuse \& Neglect.

42. Mulder T M, Kuiper K C, van der Put C E, Stams G \& Assink M. (2018). Risk factors for child neglect: A meta-analytic review. Child abuse \& neglect. 77:198-210.

43. Newcomb M D, \& Locke T F. (2001). Intergenerational cycle of maltreatment: a popular concept obscured by methodological limitations. Child Abuse \& Neglect. 25(9):1219-1240.

44. Pearl P S. (2002). Child neglect and abandonment. In A. P. Giardino \& E. R. Giardino, Recognition of child abuse for the mandated reporter. 55-61.

45. Pears K. C, \& Capaldi D M. (2001). Intergenerational transmission of abuse: a two generational prospective study of an at-risk sample. Child Abuse \& Neglect. 25(11): 1439-1461.

46. Polansky N. A, Borgman R. D \& Saix C. D. (1972). Roots of futility. Jossey - Bass.

47. Polansky N. A, Chalmers M A, Buttenwieser E. W \& Williams D. P. (1983). Damaged parents: An anatomy of child neglect. University of Chicago Press.

48. Putnick D. L, Bornstein M. H, Lansford J. E, Chang L, DeaterDeckard K, Giunta LD, Gurdal S, Dodge K. A, Malone P.S, Oburu P. O, Pastorelli C, Skinner A T, Sorbring E, Tapanya S, Tirado L M U, Zelli A, Alampay L. P, Al-Hassan S. M, Bacchini D \& Bombi A S. (2012). Agreement in mother and father acceptance-rejection, warmth, and 
hostility/rejection/neglect of children across nine countries. Cross-Cultural Research. 46(3):191-223.

49. Raman S, \& Hodes D. (2011). Cultural issues in child maltreatment. Journal of Paediatrics and Child Health. 48(1):30-37.

50. Shanahan M, Runyan D, Martin S, \& Kotch J. (2017). The within poverty differences in the occurrence of physical neglect. Children and Youth Services Review. 75:1-6.

51. Sharpe T. T. (2005). Behind the eight ball: Sex for crack cocaine exchange and poor black women.

52. Smith M \& Fong R. (2004). The children of neglect. New York: Brunner.

53. Sphor HL, \& Steinhausen HC. (2011). Alcohol, pregnancy and the developing child. Cambridge University Press.

54. Stevenson O. (2007). Neglected children and their families. Blackwell Publishing.

55. Stevenson O. (2007). Neglected children and their families. Blackwell.

56. Stith SM, Liu T, Davies LC, Boykin EL, Alder MC, Harris JM, Som A, McPherson M \& Dees J E M E G. (2009). Risk factors in child maltreatment: A meta-analytic review of the literature. Aggression and Violent Behavior. 14(1):13-29.

57. Straussner S. L, \& Fewell C. H. (2006). Impact of substance abuse on children and families: Research and practice implications. Haworth Press.

58. Taylor J \& Daniel B. (2005). Child neglect: Practice issues for health and social care.
59. Thornberry T P, Knight K. E, \& Lovegrove P J. (2012). Does maltreatment beget maltreatment? a systemic review of the intergenerational literature. Trauma, Violence \& Abuse. 13(3), 135-152.

60. U.S. Department of Health and Human Services, Administration for Children and Families, Administration on Children, Youth and Families, Children's Bureau. (2011). Child maltreatment 2010.

61. United States Department of Health \& Human Services, Administration for Children and Families, Administration on Children, Youth and Families, Children's Bureau (2019). Child maltreatment 2017.

62. Valentino K, Nuttall A. K, Comas M, Borkowski J G, \& Akai C. E. (2012). Intergenerational continuity of child abuse among adolescent mothers: authoritarian parenting, community violence, and race. Child Maltreatment. 17(2):172-181.

63. Van de Kooij I W, Nieuwendam J, Moerman G, Boer F, Lindauer R J. L, Roopnarine J L, \& Graafsma T. L. G. (2017). Perceptions of corporal punishment among creole and maroon professionals and community members in Suriname. Child Abuse Review. 26(4):275-288.

64. Wolock I \& Horowitz B. (1979). Child maltreatment and maternal deprivation among AFDC recipient families. Social Service Review. 53(2):175-184.

65. Wright C. (2005). What is weight faltering ("failure to thrive") and when does it become a child protection issue? In J. Taylor $\&$ B. Daniel, Child neglect: Practice issues for health and social care. 166-185.

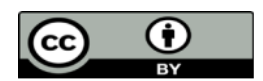

This work is licensed under Creative Commons Attribution 4.0 License
Ready to submit your research? Choose Auctores and benefit from:

$>$ fast, convenient online submission

$>$ rigorous peer review by experienced research in your field

$>$ rapid publication on acceptance

$>$ authors retain copyrights

$>$ unique DOI for all articles

$>$ immediate, unrestricted online access

At Auctores, research is always in progress.

Learn more https://auctoresonline.org/journals/international-journal-of-clinicalcase-reports-and-reviews 